The Egyptian Journal of Hospital Medicine (January 2020) Vol. 78 (2), Page 253-256

\title{
Mandibular Canine Index: A Reliable Predictor for Gender Identification Using Study Cast in North Saudi Sakaka Population ${ }^{1}$ Shilpa S Magar, ${ }^{2}$ Shaliputra P. Magar, ${ }^{3}$ Omar Hadi, ${ }^{4}$ Faries Al Turqik, \\ ${ }^{4}$ Nawaf S. Alanazi ${ }^{4}$ Rakan M. Albilasi
}

1. Department of Operative Dentistry and Endodontic, 2. Department of Oral and Maxillofacial Surgery, 4. Oral Medicine \& Radiology, Jouf University, College of Dentistry Sakaka, KSA

Corresponding Author: Dr Shaliputra P. Magar, Mobile:+966568522659, Email: shaliomdr@gmail. com

\begin{abstract}
Background: Various methods are used for gender identification in anthropologic and forensic investigations. The canine tooth are widely used for gender determination because of its sexual dimorphism and durability in oral cavity. Mandibular canine index is one of the most reliable and valid predictor for gender identification.

Aim: To assess the reliability of Mandibular Canine Index in gender determination in North Saudi Sakaka populations. Settings and Design: This was an experimental study involving the preparation of plaster cast models on 100 individuals residing in North Saudi Sakaka populations. Out of these 55 were males and 45 were females. Both sexes were in the age group of 20-40 years old. Study casts were prepared for all individuals and the measurements of mandibular canine teeth were taken. The Mandibular canine index was calculated using standardized equation. In addition, the percentage of sexual dimorphism was calculated. Independent sample $t$ test was used. P value $<0.05$ was considered statistically significant. Results: There was a significant difference ( $p$ value $<0.05$ ) observed between intercanine distance, right and left canine width and right and left mandibular canine index between males and females. Sexual dimorphism was more on left permanent mandibular canine teeth than right permanent mandibular canine teeth. The overall percentage of accuracy observed was $85.5 \%$.

Conclusions: Study findings revealed that mandibular canine index can be used as a reliable predictor for gender determination in Sakaka population and can form the basis of anthropologic and forensic investigations.

Keywords: Mandibular canine index, Sexual dimorphism, Inter canine distance.
\end{abstract}

\section{INTRODUCTION}

In cases of mass disasters or major catastrophes, where the bodies are mutilated beyond recognition, the dimorphism in mandibular canines play a significant role in gender identification. The only method that can give a totally accurate result is the DNA technique, but in many cases for several reasons it cannot be used. Teeth used in odontometric analysis, are an excellent material in living and non-living populations for anthropological, genetic, odonatological and forensic investigations. Their durability in the face of fire and bacterial decomposition makes them invaluable for identification. Mandibular canines exhibit the greatest sexual dimorphism amongst all teeth ${ }^{1}$.

Sexual dimorphism refers to those differences in size, stature and appearance between male and female that can be applied to dental identification because no two mouths are alike ${ }^{2}$. However, differences in tooth size, variations in root length and crown diameter, dental index, odontometric differences, barr bodies and using enamel protein have also been tried for sex determination. Human teeth are the hardest and chemically the most stable tissues in the body, and are extremely durable even at higher temperatures. Teeth can be identified even when the rest of the body has undergone decomposition as in case of using soft tissue structures for gender identification. They are therefore invaluable for identification on fragmentary adult skeleton ${ }^{3}$.

Sex determination using dental features is mainly based upon the comparison of tooth dimensions in males and females ${ }^{2}$. The 4 Mandibular canines are found to exhibit the greatest sexual dimorphism among all teeth because of the following reasons:

1. Canines are less exposed to plaque and calculus.

2. Less severely affected by periodontal disease.

3. Lesser pathological migration of mandibular canines than other teeth.

4. Canines are the last teeth to be extracted with respect to age.

5. Canines are more likely to survive in conditions such as air disasters and hurricanes ${ }^{1}$.

The present study establishes the impact of the 'sex factor' on the morphometry of the mandibular canines. The dimorphism in maxillary canines can be of immense medico-legal use in gender identification. The study defines the morphometric criteria for mandibular canines in North Saudi Sakaka population.

\section{SUBJECTS AND METHOD}

This study was carried out on 100 individuals residing in North Saudi Sakaka population. Out of these 55 were males and 45 were females. Both sexes belong to age group between 20 - 40 years old. 
The inclusion criteria: Patients having healthy periodontium, caries free canine teeth and teeth having class I canine relationship.

Exclusion criteria: Patients having carious or missing mandibular anterior teeth, presence of abrasion, attrition, spacing and crowding in mandibular anterior teeth and hard tissue diseases affecting the mandibular anterior teeth.

Mandibular impressions of all the samples were made with alginate and study models were prepared with dental stone. Mandibular study models were used for the analysis. On the study model following measurements were taken. Mandibular canine width was measured as the greatest mesio-distal dimension of mandibular canine on either side of the jaw using a digital vernier caliper (Fig 1).

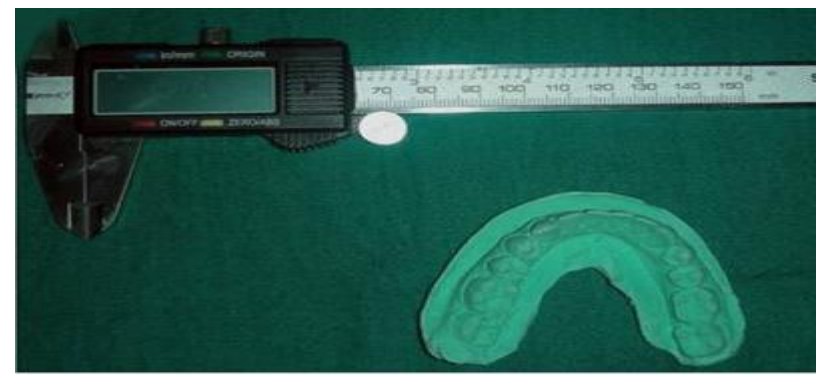

Fig (1): Shows digital vernier caliper and study cast to measure the mandibular canine width.

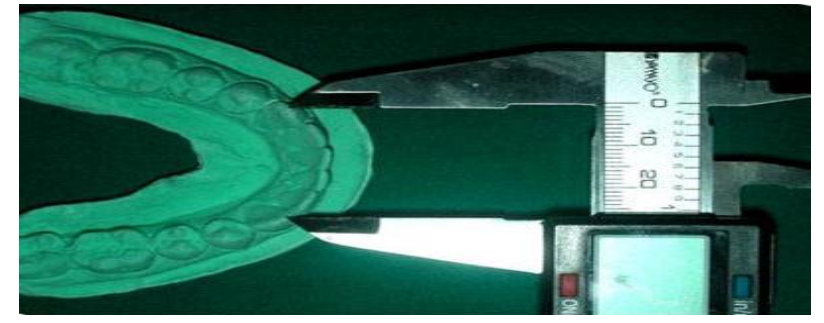

Fig (2): For measuring the mesio-distal width of the canine, the vernier caliper was held parallel to the plane of occlusion.

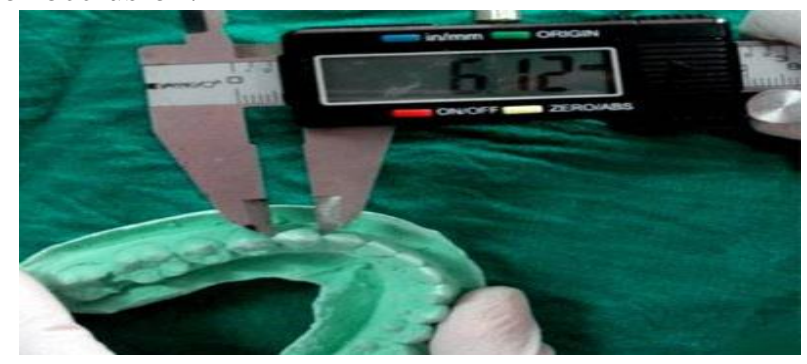

Fig (3): The intercanine distance was measured as the linear distance between the cusp tips of right and left mandibular canine. The readings obtained after measurement of left and right mandibular canine width and intercanine distance were subjected to statistical analysis to assess the mandibular canine indices
The formula used to determine Canine Index and sexual dimorphism were:Observed mandibular canine index $\left(\mathrm{MCI}_{0}\right)=$ mesio-distal crown width of mandibular canine/ inter canine distance ${ }^{5}$.

Standard mandibular canine index $($ MCIs $)=($ Mean male MCI - SD $)+($ Mean female MCI $+\mathrm{SD}) / 2^{5}$.

Sexual Dimorphism $=\left(\mathrm{X}_{\mathrm{m}} / \mathrm{X}_{\mathrm{f}}\right)-1 \times 100^{6}$

Where $X_{m}=$ Mean value of male canine width $X_{\mathrm{f}}=$ Mean value for female canine width

\section{Statistical analysis}

The readings obtained were subjected to statistical analysis to assess sex difference using unpaired t-test. Statistical analysis was done regarding intercanine distance, right canine width, left canine width, right mandibular canine index, left mandibular canine index, observed and standard MCI and Sexual dimorphism.

\section{RESULTS}

The study involved the preparation of 100 plaster casts from 55 males and 45 females' participants. The Intercanine distance was measured from the cusp tip of right and left mandibular canine using standardized criteria. The results showed that the mean value of the intercanine distance in males was $28.14 \pm 4.06 \mathrm{~mm}$ with the coefficient of variation observed to be 0.66 which was significantly higher $(\mathrm{t}$ value $=4.16, \mathrm{p}$ value $<0.001)$ than the mean value and coefficient of variation reported in females. In females the mean value of the intercanine distance was found to be $25.70 \pm 1.40 \mathrm{~mm}$ with coefficient of variation found to be 0.08 .

The mean values of the width of right canine and left canine as measured using a Vernier calipers in males was found to be 7.19 and $7.32 \mathrm{~mm}$ with coefficient of variation to be 0.20 and 0.23 respectively. These were found to be significantly higher ( $\mathrm{p}$ value $<0.05$ ) than those reported in females. The mean value of the width of right canine and left canine in females were found to be 6.30 and $6.35 \mathrm{~mm}$ respectively.

The mandibular canine index was calculated using a standardized formula. In males the Mandibular canine index on the right side was found to be $0.26 \mathrm{~mm}$ with coefficient of variation of 0.15 . Whereas on the left side, it was found to be 0.26 with coefficient of variation of 0.18. In females the Mandibular canine index on the right side was found to be $0.25 \mathrm{~mm}$ whereas on the left side it was found to be $0.25 \pm 1.40 \mathrm{~mm}$. The value of the calculated Mandibular canine index was found to be significantly higher in males compared to females on both right and left sides. Overall, the values obtained for the Intercanine distance, right canine width, left canine width, right mandibular canine index and left mandibular canine index was found to be significantly higher in males than females (Table 1). 
Table (1): Shows mean and standard deviation among Inter-canine distance, Right and left canine width and Right and left mandibular canine index.

\begin{tabular}{|c|c|c|c|c|c|c|c|}
\hline $\begin{array}{l}\text { S. } \\
\text { No }\end{array}$ & Parameters & Sex & Mean & \pm S.D & $\begin{array}{l}\text { Coefficient of } \\
\text { variation }\end{array}$ & t-stat & P-value \\
\hline 1. & Inter-canine distance & $\frac{\mathrm{M}}{\mathrm{F}}$ & $\frac{28.14}{25.70}$ & $\frac{4.06}{1.40}$ & $\frac{0.66}{0.08}$ & 4.16 & $<0.001 * *$ \\
\hline 2. & Right canine width & $\frac{\mathrm{M}}{\mathrm{F}}$ & $\frac{7.19}{6.30}$ & $\frac{2.23}{0.35}$ & $\frac{0.20}{0.00}$ & 2.92 & $<0.05^{*}$ \\
\hline 3. & Left canine width & $\frac{\mathrm{M}}{\mathrm{F}}$ & $\frac{7.32}{6.35}$ & $\frac{2.46}{0.35}$ & $\frac{0.23}{0.00}$ & 2.82 & $<0.05 *$ \\
\hline 4. & $\begin{array}{lll}\text { Right mandibular cani } \\
\text { index }\end{array}$ & $\frac{\mathrm{M}}{\mathrm{F}}$ & $\frac{0.26}{0.25}$ & $\frac{1.88}{0.35}$ & $\frac{0.15}{0.00}$ & 2.56 & $<0.05^{*}$ \\
\hline 5. & $\begin{array}{lll}\text { Left mandibular cani } \\
\text { index }\end{array}$ & $\frac{\mathrm{M}}{\mathrm{F}}$ & $\underline{0.26}$ & $\frac{2.13}{0.35}$ & $\underline{0.18}$ & 2.67 & $<0.05^{*}$ \\
\hline
\end{tabular}

$* p$ value $<0.05$; significant difference ${ }^{* *} p$ value, 0.05; highly significant difference

\section{DISCUSSION}

In the present study, there was a significant difference observed between the right canine width and the left canine width of males and females. Similar results were obtained in the previous studies done by Kaushaletal and Vandana ${ }^{(1)}$ and Reddy et al. ${ }^{[7]}$. The difference in width of canine between male and female teeth has been explained as part of the genetic expression of the male being larger than the female. It is the Y chromosome, which intervenes most in the size of teeth by controlling the thickness of dentin, whereas the $\mathrm{X}$ chromosome is responsible for the thickness of enamel. The sexual dimorphism in mandibular canines can be expected to be based on functional activity due to evolution and socialization.

In the present study, there was a highly significant difference between intercanine distance of males and females. The study findings also revealed that there was a significant difference between the right and left mandibular canine index among males and females. Similar findings were also reported in the studies done by Kaushaletal and Vandana ${ }^{(1)}$ and Patnaik et al. ${ }^{[5]}$. The contribution of various tissues in sexual dimorphism of tooth size was reported by Harris et al. ${ }^{(8)}$. They found that males typically have significantly larger dentine and pulp dimensions than females, while marginal enamel thickness is similar in both sexes. Moss et al. ${ }^{(9)}$ suggested that dimorphism is related to an absolutely longer period of amelogenesis for both deciduous and permanent dentitions.

Garn et al. ${ }^{(6)}$ concluded that the mandibular canine exhibited the greatest sexual dimorphism amongst all teeth $\left(6.47 \%\right.$ and $5.7 \%$ respectively). Nair et al. ${ }^{(10)}$ in their study done on South Indian subjects reported that the left mandibular canine exhibited a sexual dimorphism of $7.7 \%$ while the right mandibular canine was $6.2 \%$.

In the present study also, the left mandibular canine was found to exhibit greater sexual dimorphism (15.2\%) as compared to the right mandibular canine $(14.1 \%)$. Thus, usage of left mandibular canine to estimate the gender of the individual will give more precise results.

In the present study, the percentage of accuracy obtained by comparing observed mandibular canine index with standard mandibular canine index using both right and left sides was $83.8 \%$ in males and $87.2 \%$ in females. The overall percentage of accuracy was $85.5 \%$. The study finding were close to the percentage of accuracy obtained by Nair et al. ${ }^{(10)}$ in their study done in south Indian population, where they found the accuracy to be $84.3 \%$ in males and $87.5 \%$ in females.

\section{CONCLUSION}

The significant results obtained on comparison of right and left mandibular canine indices in males and females justify its usage as a tool for the determination of sex of an individual. The findings indicated that the dimorphism in mandibular canines can be of immense medico-legal use in gender identification.

\section{REFERENCES}

1. Kaushal S, Patnaik VVG, Agnihotri G (2003): Mandibular Canines in Sex Determination. J. Anat. Soc. India, 52 (2): 119-24.

2. Parekh DH, PatelS V, Zalawadia AZ (2012): Odontometric Study of Maxillary Canine Teeth to Establish Sexual Dimorphism in Gujarat Population. Int J Biol Med Res., 3 (3): 1935-37.

3. Kapila R, Nagesh KS, Iyengar R A, Mehkri S (2011): Sexual dimorphism in human mandibular canines: 
radiomorphometric study in South Indian population. J Dent Res Dent Clin Dent Prospects, 5 (2): 51-4.

4. Vodanovic M, Demo Z, Njemirovskij V, Keros J, Brkic H (2007): Odontometrics: a useful method for sex determination in an archaeological skeletal population. J Arc Sci., 34: 905-913.

5. Patnaik VVG, Kaushal S, Sood V, Agnihotri G (2004) Sex Determination in North Indians using Mandibular Canine Index. JIAFM., 26(2): 45-49.

6. Garn SM, Lewis AB, Kerewsky RS (1967): Buccolingual size asymmetry and its developmental meaning. , 37 (3): 186-93.

7. Reddy VM, Saxena S, Bansal P (2008): Mandibular canine index as a sex determinant: A study on the population of western Uttar Pradesh. JOMFP., 12 (2): 5659.

8. Harris EF, Hicks JD, Barcroft BD (2001): Tissue contributions to sex and race: differences in tooth crown size of deciduous molars. Am J PhysAnthropol., 115 (3): 223-37.

9. Moss ML, Salentijn ML (1977): Analysis of developmental processes possibly related to human dental sexual dimorphism in permanent and deciduous canines. Amer J PhysAnthropol., 46: 407-13.

10. Nair P, Rao BB, Annigeri R (1999) A study of tooth size, symmetry and sexual dimorphism. J Foren Med Tox., 16 (2): 10-13. 